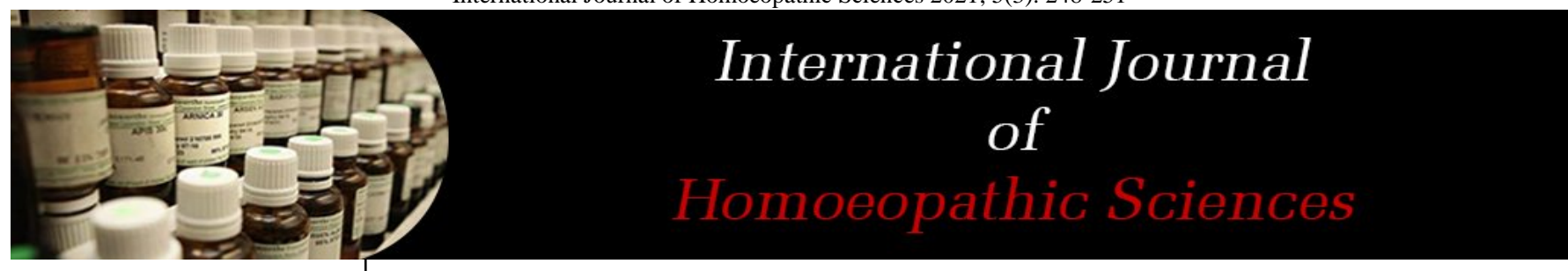

E-ISSN: $2616-4493$

P-ISSN: 2616-4485

www.homoeopathicjournal.com IJHS 2021; 5(3): 248-251

Received: 20-05-202

Accepted: 22-06-2021

Dr. Shraddha Khanna

Assistant Professor, Department of Organon of Medicine, Bakson Homoeopathic Medical College and Hospital, Greater Noida,

Uttar Pradesh, India
Corresponding Author: Dr. Shraddha Khanna Assistant Professor, Department of Organon of Medicine, Bakson Homoeopathic Medical College and Hospital, Greater Noida, Uttar Pradesh, India

\section{Treating postpartum depression with homeopathy}

\author{
Dr. Shraddha Khanna
}

DOI: https://doi.org/10.33545/26164485.2021.v5.i3d.430

\section{Abstract}

Postpartum depression is one of the critical problems being faced in today's time. Manifested by symptoms like depressed mood, anxiety, poor appetite, loss of concentration and insomnia, the exact mechanism of its development remains unknown. Conventional treatment with antidepressants and hormones carries the risk of having side-effects. Homeopathy provides a safe and gentle remedial means for the treatment of postpartum depression. Individualization in remedy selection can help us bring significant cures and help women in their journey of motherhood.

Keywords: Postpartum depression, homeopathy, individualization

\section{Introduction}

Postpartum depression is a mental health problem which develops gradually during the first six months of delivery or abortion 1 American Psychological Association (APA) defines it as “ A serious mental health problem characterized by a prolonged period of emotional disturbance, occurring at a time of major life change and increased responsibilities in the care of the new born" [2].

Postpartum depression (PPD) is manifested by symptoms like sad mood, anxiety, loss of sleep, loss of appetite, social withdrawal and irritability. There is a high likelihood of its recurrence in subsequent pregnancies or experiencing recurrent depressive episodes later in life ${ }^{[1,3]}$. It is observed that children born to such mothers have delayed language and cognitive development.

Further, mother's ability to take care of the baby and crucial activities like breastfeeding are also seriously impaired ${ }^{[3]}$.

While the global incidence of PPD was found to be $12-13 \%{ }^{[4]}$. The estimated prevalence of PPD in Indian mothers, as per a systematic and meta-analysis study is $22 \% .5$ The incidence is high in low and lower-middle-income countries, 5 the reason being lack of awareness about PPD among health professionals and non-institutional deliveries ${ }^{[3]}$.

A number of contributory factors can impact a woman simultaneously during her Postpartum period such as low socioeconomic status, any previous history of depression, premenstrual syndrome, episodes of anxiety and depression during pregnancy, postpartum blues, and lack of social and emotional support at home, history of domestic violence, abortion or birth of a female baby ${ }^{[6,7]}$.

Any problems related to the child such as birth of a preterm baby or a baby born with congenital defects may also trigger episodes of depression in the new mother ${ }^{[7]}$.

While the exact mechanism of its development is not known yet, 8 theories related to hormonal dysregulations, abnormalities in hypothalamic-pituitary-adrenal axis activity with contribution of genes, playing key roles in development of PPD have come up.9 Disturbances in other endocrinological system has also been implicated to cause PPD such as thyroxine levels in lower euthyroid range, hypercortisolism and reduced levels of lactogenic hormones, Oxytocin and Prolactin ${ }^{[10]}$.

\section{Clinical aspects and the probable effects over mother-child bonding}

A woman with PPD may present with minor to major depressive symptoms. PPD can have an impact over the emotional, cognitive and neurovegetative aspect of a woman's behaviour ${ }^{[8]}$.Symptoms include crying, helplessness, and emotional lability, loss of appetite, sleep disturbances, poor concentration, memory, fatigue and irritability ${ }^{[11]}$. Some women experience excessive concern about baby's health, develop fear of harming the baby, guilt about maternal deficiencies and marital tensions ${ }^{[12]}$. 


\begin{tabular}{|c|c|}
\hline \multicolumn{2}{|c|}{ Possible Effects of Maternal Depression on Children's Behaviours [8] } \\
\hline $\begin{array}{l}\text { Mother } \\
\text { Unable to enjoy with the baby } \\
\text { Feeling disinterested towards the baby } \\
\text { No active interaction } \\
\text { Negative face-to-face encounters } \\
\text { Unable to pacify the baby } \\
\text { Refuses to look at or hold the baby }\end{array}$ & $\begin{array}{l}\text { Baby } \\
\text { May react violently or regressively } \\
\text { Behaves more fussy or drowsy } \\
\text { Does not make eye contact with the mother } \\
\text { Reciprocates less to the mother }\end{array}$ \\
\hline
\end{tabular}

\section{How to diagnose?}

PPD may be diagnosed on the basis of appearance of depressive symptoms amongst the postnatal women in the first 6 months after childbirth or even during the entire postpartum year. 13 one also needs to identify etiological factors such as social or psychological changes following childbirth that could be implicated in development of such symptoms ${ }^{[12]}$.

As the postpartum disturbances do not differ significantly from affective illnesses that occur in women at other times, PPD is therefore diagnosed with the help of Diagnostic \& Statistical Manual -V \& International Classification of Diseases -10 , the currently used system of classification of mental disorders. Both the systems have specifiers to identify affective disorders during post- partum period ${ }^{[11]}$. PPD in most cases can be prevented and treated with early identification of the condition.

Therefore, women should be screened by their physicians to determine their risk for acquiring PPD.6 The Edinburgh Postnatal Depression Scale is the most extensively used scale for this purpose. Other scales which may be used for this purpose are Beck Depression Inventory (BDI), Bromley Postnatal Depression Scale (BDI-II) and Patient Health Questionnaire-9.14 Screening of PPD is effective when carried out by professionals in obstetrics/gynaecology or Paediatrics department. Mothers are more likely to attend Paediatrics appointments rather than their own routine postpartum checks ${ }^{[13]}$.

There may be various other disorders that mimic PPD in its manifestations which should be differentiated and treated accordingly. Differential diagnosis for PPD may include Postpartum blues, Postpartum Psychosis, Bipolar disorders and Anxiety disorders [13]

\section{Management of Ppd}

Women with PPD are usually treated on the same lines as a woman with non-puerperal major depression. In conventional system, Antidepressants and hormonal therapy in the form of oestrogen and progesterone are provided.15 There are evidences that show that intake of antidepressants is associated with short and long-term side-effects such as nausea, anxiety, insomnia, weight gain, lethargy and sexual side-effects ${ }^{[16]}$.

Homoeopathic medicines have convincing evidence in the treatment of depression ${ }^{[17-19]}$

Homoeopathic management pays respect to the less overt aspects of depression, the causation behind it. The vital force is disturbed and homoeopathy balances this subtle level of energy, that too without side-effects ${ }^{[20]}$.

PPD originates from a mental cause. Our Master Hahnemann described in detail about case taking of socalled mental diseases in Aphorisms 210-230, in his book Organon of Medicine. According to him, all types of mental diseases belongs to Psoric miasm. Hahnemann says, these mental disorders that arise and are kept up by emotional causes, such as continued anxiety, worry, vexation, wrongs and frequent occurrence of great fright, in time destroys the corporeal health often to a great degree and therefore should be treated while they are yet recent ${ }^{[21]}$.

Psychotherapy Psychotherapy is a talk therapy where in people facing mental health issues and emotional difficulties are there by helped to cope up with them and lead a better and healthy life. There are different types of psychotherapy such as interpersonal therapy, cognitive behavioural therapy, psychodynamic therapy and psychoanalysis [22]. Master Hahnemann has also advised that treatment of such emotional diseases that are kept up by the mind itself, by means of psychical remedies such as display of confidence, friendly persuasion, sensible advice and well disguised deception $^{\text {[21] }}$

Homoeopathic Approach Hahnemann has advised that besides treatment with Psychical remedies, following an appropriate diet and regimen is also important as a healthy mind resides only in a healthy body.

Since the fundamental cause in these cases is a psoric miasm, which is not quite developed yet, for security's sake seemingly cured patients should be subjected to a radical, Antipsoric treatment in order to prevent recurrence ${ }^{[21]}$.

Following an Individualistic approach towards the remedy selection can ensure a permanent and long-lasting cure. Indications of some of the remedies for PPD are mentioned hereby:

\section{Sepia}

Sepia is especially adapted to diseases of women, occurring during pregnancy and childbed, attended with sudden prostration and sinking faintness. There is anxiety due to fear, about real or imaginary things, especially towards evening. She beats his small son and does not care while her baby cries. She wants to run away and leave everything and have some peace. Sepia has abolished the ability to feel natural love, to be affectionate. This state often comes when nursing a child, or nursing an over-vigorous child or twins that require much lacteal fluid and drag her down. Answers questions in monosyllables ${ }^{[23-25]}$.

\section{Pulsatilla}

Pulsatilla is specially adapted for diseases of women, who are affectionate, mild, timid, yielding.

Impossible to detail her ailments without weeping. There is a tendency to inward grief and silent peevishness. She dreams of cats. Hypochondriacal moroseness, takes everything in bad part. Puerperal insanity in a woman who was mild and gentle, later sad and taciturn and then she sits in her chair all day answering nothing or merely nodding her head for "yes” or "no". For women who abort or have 
false conception. Mental symptoms ameliorated while walking in open air ${ }^{\text {[23-25] }}$

\section{Aurum Metallicum}

Aurum woman is constantly dwelling on suicide. There is profound melancholy, feels hateful and quarrelsome. Life is a constant burden for her. Woman feels dejected, seeks solitude. Imagines she is not fit for the world, longs for death. Thoughts of death gives her immense joy, seeks methods to commit suicide. Insanity begins in the will and proceeds to the intellect. Self-condemnation, continual selfreproach. Imagines she has neglected her duty and in consequence deserves reproach. Absorbed in herself, sits and broods over it and intensifies her present state ${ }^{\text {[23-25] }}$

\section{Ignatia Amara}

Ignatia women are sensitive, of mild disposition, quick to perceive, rapid in execution. Easily offended by slightest contradiction. Mentally exhausted from long concentrated grief. Involuntary sighing. Broods in solitude over imaginary trouble. Desires to be alone. Ignatia is not suitable for women in whom anger, eagerness or violence predominates, but for those who are subject to rapid alterations of gaiety and disposition to weep. As per Dr. Kent, "it is best to administer small dose in the morning, if there is no urgency. When given shortly before bedtime it causes too much restlessness" [23-25].

\section{Natrium Muriaticum}

Natrium Mur woman has a sad, weeping mood, without a cause, but consolation from others aggravates her troubles. Irritability, gets into passion about trifles. She tries to remember old disagreeable, old insults, for purpose of brooding over them and being miserable. She has unrequited affections, knows they are unwise, but can't help it. Falls in love with wrong person, a coachman or a married man and breaks her heart. Natrum mur brings order and sanity in such women. These women hide their tears for fear of pity and consolation ${ }^{[23-25]}$

\section{Platina}

Platina women are hysterical, arrogant, proudy and contemptuous. Trifling things produce profound vexation, remains long time in sulks. There is satiety of life with taciturnity and fear of death. Women who have perverted mentality, an attitude that despises others and goes about thanking God that she is not as other people. She secretly dislikes her children as being too small or too insignificant. Ailments from fright, prolonged excitement, disappointment, shock or prolonged haemorrhage. She thinks she is neglected and stands alone in the world. Depression increases to actual apprehension of death. Makes every arrangement for the disposition of her affairs after death ${ }^{\text {[23-25] }}$

\section{Actea Racemosa}

It is a remedy of crazy feelings. Incessant talking, changing from one subject to another. Feels grieved and troubled one day, next day joy and playfulness. Imagines strange objects around her bed, rats, mouse, sheep etc. Mental depression, suicidal after checked neuralgia. She is despondent and feels as if under a black cloud. It is suited to women who lacks will, balance, or have a great disturbance in the voluntary system. Suspicious, will not take medicine, as there is something wrong about it. Very emotional, that if she hears an emotional story, her lochia may stop or milk be suppressed ${ }^{\text {[23-25] }}$

\section{Veratrum Album}

Puerperal mania with disposition to bite and tear. She is inconsolable over a fancied misfortune, runs around the room howling and screaming or sits brooding and weeping. For women affected with immense grief and despair, likely to go into a state of violent mania. Veratrum carries through the state of despair, melancholia, head hangs down, sits brooding in silence ${ }^{\text {[23-25] }}$

\section{Stramonium}

Stramonium women are melancholic, low spirited after childbirth. She believes she has sinned away her days of grace, yet lived an upright life. Sad, imagines strange things, does strange things, until finally violent delirium comes on; she screams aloud; exhorts people to repent; exhorts and prays in incoherent speech. Hysterical, praying, cannot bear solitude or darkness ${ }^{[23-25]}$.

\section{Lachesis}

Lachesis women stands at the border of insanity. Imagines people are trying to harm her, or making plans to put her into an asylum. Highly suspicious and jealous. Thinks she is under superhuman control and there are demands partly in dream that must be followed. Religious insanity, thinks she is wicked and has committed an unpardonable sin and must die. Loquacious ${ }^{\text {[23-25] }}$

Other Indications as Given by Different Stalwarts Dr. Richard Hughes has advised for puerperal melancholia, Platina, Pulsatilla, Aurum and Agnus castus, but he has most confidence in Actea racemose ${ }^{[26]}$.

Dr. Jahr says that these affections are readily cured by Aconitum, Aurum, Belladonna, Pulsatilla, Platina, Sulphur, Veratrum, Stramonium and Zincum. He advises dissolving these remedies in half a tumblerful of water, 6 globules of 6 th or 12th dilution, and give a dessert-spoonful of this solution every 3 hourly ${ }^{[27]}$

Representation of PPD In Different Repertories Kent Repertory 28 Mind, Sadness, pregnancy, in: Cimic, lach., nat-m. Mind, Sadness, labor, during: Cimic, ign., lach., natm., puls., rhus-t., sulph., verat., zinc.

Mind, Weeping, pregnancy, during: Apis, ign., mag-c., natm., puls., stann. Complete Repertory 29 Mind, Ailments form, Delivery, parturition, After puerperal: Bell., Plat., Verat Mind, Sadness, despondency, depression, melancholy, Delivery, parturition, After puerperal: Anac., Aur. m., Cimic., Con., Lil-t., Psor. Mind, Hysteria, Pregnancy, delivery, labor, during: Chel., Chlol., Gels. Murphy Repertory 30 Mind, Depression, Childbirth after: Agn., Anac., Aur., Cimic., Lach., Puls., SEP., Sulph. Mind, Depression, Pregnancy in: Nat. mur., Plat., Puls., Sep

Pregnancy, Depression, during: Aur. m., Nat. Mur., Puls, Sep Pregnancy, Childbirth, Hysteria, since childbirth: Chel., Gels. Pregnancy, Melancholy: Plat.

Pregnancy, Mental problems, during pregnancy: Bell, Ign., Puls, Sep. Analytical Repertory of Mind By Hering 31 Grief and sorrow; sexual organs; In pregnancy, chorea: Ignat., Stramon. Repertory of Hering' Guiding Symptoms of Our Materia Medica by Calvin B. Knerr 32

1. Puerperal, mania: Aur. Chlol., CIMIC., Kali-c., Stram., Sulph., Verat. 
2. Puerperal, mania, melancholia: Anac.

3. Mind and disposition, mania, puerperal: Aur., Bell., Camph., Chlol., CIMIC., Kali-c., Stram., Verat.

Boenninghausen's Characteristic Materia Medica \& Repertory by C.M. Boger 33

1. Genitalia, Female organs, Childbed, mental symptoms: Bell., PLAT., Pul., sul., ver-a., zin.

2. Mind, Aggravation, Child-bed, in: Aco., stra.

3. Mind, Aggravation, Puerperal state, in: Sec.-c.

4. Mind, Aggravation, Pregnancy, during: Bell., chin., con., ign., lys., nat-m., Nux-m., Pul.

\section{Conclusion}

It is a well-known fact that postpartum period is highly sensitive and stressful period in the life of a mother. These events pose an increased risk towards development of affective illnesses in the woman. Homoeopathy has always been successful in treating diseases of this kind that are kept up by some kind of fear, frustration, anger or hatred. Homoeopathic medicines are safe, gentle, non-toxic administered with holistic principles. They can provide an ideal alternative to conventional medications without any side-effect.

\section{References}

1. Dutta DC. Abnormalities of the puerperium. In: Konar H, editor. Textbook of Obstetrics. 7th ed. Kolkata: New Central Book Agency (P) Ltd 2011, 442.

2. Zaidi F, Nigam A, Anjum R, Agarwalla R. Postpartum depression in women: a risk factor analysis. J Clin Diagn Res 2017;11(8):QC13.

3. Upadhyay RP, Chowdhury R, Salehi A, Sarkar K, Singh SK, Sinha B et al. Postpartum depression in India: A systematic review and meta-analysis. Bull World Health Organ 2017;95(10):706.

4. Desai N, Mehta RY, Ganjiwale J. Study of prevalence and risk factors of postpartum depression. Natl J Med Res 2012;2(2):194-8.

5. Basu S, Budh N, Garg S, Singh MM, Sharma A. Postpartum depression burden and associated factors in mothers of infants at an urban primary health center in Delhi, India. Tzu Chi Med J 2021;33(1):70.

6. Nigam A, Prakash A, Maheshwari N. Postpartum depression in an Indian community: more prevalent less addressed issue. Int $\mathrm{J}$ Reprod Contracept Obstet Gynecol 2016;5(8):2692.

7. Mehta S, Mehta N. An overview of risk factors associated to post-partum depression in Asia. Mental illness 2014;6:5370.

8. Chaudron LH. Postpartum Depression: What paediatricians need to know. Pediatrics in review. 2003;24(5):155.

9. Meltzer-Brody S. New insights into perinatal depression: Pathogenesis and treatment during pregnancy and postpartum. Dialogues Clin Neurosci. 2011;13(1):89.

10. Schiller CE, Meltzer-Brody S, Rubinow DR. The role of reproductive hormones in postpartum depression. CNS Spectr. 2015;20(1):48.

11. Stewart DE, Robertson E, Celasun N. Risk factors for postpartum depression. In: Stewart DE., Robertson, E., Dennis, C.-L., Grace, S.L., \& Wallington, T. Postpartum depression: Literature review of risk factors and interventions. Toronto: University Health Network Women's Health Program for Toronto Public Health. 2003, 1-289.
12. Tripathy T, Prusty U, Nayak C. Homoeopathy in Mental Disorders in Postpartum Stage. Cross Current Int J Med Biosci 2020, 2(7).

13. Friedman SH, Resnick PJ. Postpartum depression: an update. Women's Health 2009;5(3):287-95.

14. Gjerdingen DK, Yawn BP. Postpartum depression screening: Importance, methods, barriers, and recommendations for practice. J.Am. Board Fam. Med. 2007;20(3):280-8.

15. Nonacs R, Cohen LS. Postpartum mood disorders: diagnosis and treatment guidelines. J Clin Psychiatry. 1998;59(2):34-40.

16. Zajecka JM. Clinical Issues in Long-Term Treatment With Antidepressants. J Clin Psychiatry 2000;61:20-5.

17. Oberai P, Balachandran I, Nair KJ, Sharma A, Singh VP, Singh V, Nayak C. Homoeopathic management in depressive episodes: A prospective, unicentric, noncomparative, open-label observational study. Indian J Res Homoeopathy 2013;7(3):116.

18. Bagherian M, Mojembari AK, Hakami M. The effects of homeopathic medicines on reducing the symptoms of anxiety and depression: randomized, double blind and placebo controlled. J Homeop Ayurv Med. 2014;3(167):2167-1206.

19. Vacaraş V, Vithoulkas G, Buzoianu AD, Marginean I, Major Z, Vacaraş V, et al. Homeopathic treatment for postpartum depression: a case report. J Evid Based Complementary Altern Med 2017;22(3):381-4.

20. A Research project presented to the faculty of health and biotechnology, tecknikon Witwatersrand, in partial fulfilment of the requirements for the master's degree (M. Tech): Homoeopathy [Unpublished]. 2012: University of Johannesburg. Retrieved from: https://ujdigispace.uj.ac.za (Accessed: 2021 May 9)

21. Hahnemann S. Organon of medicine New Delhi: B. Jain Publishers (P) Ltd. 2012, 201-202.

22. Understanding psychotherapy and how it works [Internet]. 2012 Nov 1[updated 2020 July cited 2021 May 10]. Available from: http://www.apa.org/helpcenter/understandingpsychotherapy.aspx

23. Allen HC. Allen's keynote and characteristic with comparisons with bowel nosodes. 8th ed. New Delhi: B. Jain Publishers (P) Ltd. 2012.

24. Tyler ML. Homoeopathic Drug Pictures. 2nd ed. New Delhi: B. Jain Publishers (P) Ltd 1992.

25. Kent JT. Lectures on Homoeopathic Materia Medica. New Delhi: B. Jain Publishers (P) Ltd. 2002.

26. Hughes R. The Principles and Practice of Homoeopathy. 4th ed. Leath \& Ross 1902.

27. Jahr GHG. The Homoeopathic treatment of the diseases of females and infant at the breast. $5^{\text {th }}$ ed. Calcutta: M.Bhattacharya \& Co. (P) Ltd 1986.

28. Kent JT. Repertory of the Homoeopathic Materia Medica. New Delhi: B. Jain Publishers (P) Ltd. 2012;77:94.

29. Zandvoort RV. Complete Repertory. Hompath 1996.

30. Robin M. Homoeopathic Medical Repertory. New Delhi: B. Jain Publishers (P) Ltd 2004, 1307.

31. Hering C. Analytical Repertory of the Symptoms of Mind. New Delhi: B. Jain Publishers (P) Ltd. 1995, 86.

32. Knerr CB. Guiding symptoms of our Materia Medica New Delhi: B. Jain publishers (P) Pvt. Ltd. 2012, 701.

33. Boger CM. Boger Boenninghausen's Characteristic and Repertory New Delhi: B. Jain Publishers (P) Ltd. 2015, 191-227. 